\title{
Management and educational status of adult anaphylaxis patients at emergency department
}

\author{
Mi-Yeong Kim ${ }^{1}$, Chan Sun Park² , and Jae-won Jeong ${ }^{3}$
}

${ }^{1}$ Department of Internal Medicine, Inje University Busan Paik Hospital, Busan; ${ }^{2}$ Department of Internal Medicine, Inje University Haeundae Paik Hospital, Busan; ${ }^{3}$ Department of Internal Medicine, Inje University Ilsan Paik Hospital, Goyang, Korea
Background/Aims: We evaluated the management and educational status of adult anaphylaxis patients at emergency departments (EDs).

Methods: Anaphylaxis patients who visited ED from 2011 to 2013 were enrolled from three hospitals. We analyzed clinical features, prior history of anaphylaxis, management and provided education for etiology and/or prevention. For analyzing associated factors with epinephrine injection, Pearson chi-square test was used by SPSS version 21 (IBM Co.).

Results: A total of 194 anaphylaxis patients were enrolled. Ninety-nine patients (51\%) visited ED by themselves. Time interval from symptom onset to ED visit was $62 \pm 70.5$ minutes. Drug (56.2\%) was the most frequent cause of anaphylaxis. Forty-seven patients $(24.2 \%)$ had prior history of anaphylaxis and 33 patients had same suspicious cause with current anaphylaxis. Cutaneous (88.7\%) and respiratory (72.7\%) symptoms were frequent. Hypotension was presented in 114 patients (58.8\%). Mean observation time in ED was $12 \pm 25.7$ hours and epinephrine was injected in 114 patients (62\%). In 68 patients, epinephrine was injected intramuscularly with mean dose of $0.3 \pm 0.10 \mathrm{mg}$. Associated factor with epinephrine injection was hypotension $(p=0.000)$. Twenty-three patients $(13 \%)$ were educated about avoidance of suspicious agent. Epinephrine auto-injectors were prescribed only in five patients. Only 34 (19\%) and 72 (40\%) patients were consulted to allergist at ED and outpatient allergy department respectively.

Conclusions: We suggested that management and education of anaphylaxis were not fully carried out in ED. An education and promotion program on anaphylaxis is needed for medical staff.

Keywords: Patient care management; Education; Professional; Anaphylaxis; Emergency medical services

\section{INTRODUCTION}

Anaphylaxis is a serious generalized hypersensitivity reaction that could lead to death and occurs through an immunologic or non-immunologic mechanism $[1,2]$. This condition is very rare and the true prevalence is unknown because of underdiagnosis [2]. In international studies, the lifetime prevalence of anaphylaxis was estimated at $0.05 \%$ to $2 \%[3]$. In Korea, according to a recent multicenter study [4], the prevalence of anaphylaxis was 13.30 cases per 100,000 adult patients visiting hospitals and 47.33 cases per 100,000 adult visitors in emergency departments (EDs) in 2011. It is not easy to notice the cause of anaphylaxis in some patients, and in these patients, the opportunity for appropriate management could be missed. Thus, clarifying the cause of anaphy- 
laxis and providing education to avoid suspicious causes are very important in the prevention of anaphylaxis recurrence especially in an emergent setting. In addition, doctors should help patients to avoid triggering factors and educate them on how to use epinephrine auto-injectors in emergency situations. We collected the medical record data of anaphylaxis patients and evaluated whether management and education were done appropriately at three domestic university hospital EDs.

\section{METHODS}

\section{Participants and data collection}

Adult patients (age over 18-year-old) who visited the EDs from 2011 to 2013 were enrolled from two tertiary hospitals and one secondary hospital in Korea. We reviewed the electronic medical records retrospectively by searching for the following International Statistical Classification of Disease (ICD) codes for the anaphylaxis group: anaphylactic shock/anaphylaxis (T78.0), anaphylaxis, unspecified ( $\mathrm{T}_{78.2}$ ), anaphylactic shock due to serum (T80.5) and anaphylactic shock due to adverse effect from the correct drug or from medicament properly administered (T88.6), and for additional diagnoses, insect allergy (T63.4), food allergy (T87.1), allergy angioedema ( $\mathrm{T}_{78.3)}$, allergy ( $\left.\mathrm{T}_{7} 8.4\right)$, antibiotics, aspirin, contrast media, drug, nonsteroidal anti-inflammatory drug allergy (T88.7), other urticaria (L50.88), acute urticaria (L50.9), and anaphylactic reaction due to arthropod bite (T63.4). We re-confirmed a diagnosis of anaphylaxis according to the diagnostic criteria described below in all collected cases. However, we did not exclude patients who were diagnosed as anaphylaxis by their clinician even if their information was insufficient. Clinical information about clinical features, prior history of anaphylaxis, management and education was collected.

This study was approved as deliberation exemption by the Institutional Review Board of Inje University Busan Paik Hospital (IRB No. 14-0097). This study based on medical record, so there was no need for informed consent.

\section{Diagnostic criteria of anaphylaxis}

We used the diagnostic criteria according to the anaphylaxis guideline of the World Allergy Organization(WAO)
[5]. Anaphylaxis is highly likely when any one of the following criteria here is fulfilled: (1) sudden onset of an illness, with involvement of the skin, mucosal tissue, or both and at least one of the following: sudden respiratory symptoms and signs or sudden reduced blood pressure (BP) or symptoms of end-organ dysfunction; (2) two or more of the following that occur suddenly after exposure to a likely allergen or other trigger for that patient: sudden skin or mucosal symptoms and signs, sudden respiratory symptoms and signs, sudden reduced BP or symptoms of end-organ dysfunction or sudden gastrointestinal symptoms; and (3) reduced BP after exposure to a known allergen for that patient.

\section{Statistical analysis}

Statistical analyses were performed with SPSS version 21.o (IBM Co., Armonk, NY, USA). We did statistical analyses using linear regression and independent samples $t$ test to evaluate associated factors about the duration of the emergency room stay. Pearson chi-square test was used to analyze associated factors with the injection of epinephrine. Results were considered significant when two-sided $p$ values were $<0.05$.

\section{RESULTS}

\section{Clinical characteristics of the patients}

We enrolled 194 anaphylaxis patients who were diagnosed as anaphylaxis at our hospitals or at transferred hospitals. One hundred and eighty-five patients (95.4\%) fulfilled the criteria according to the World Health Organization (WHO) criteria, but nine patients could not be assessed because of insufficient information (Supplementary Table 1). The characteristics of the anaphylaxis patients are described in Table 1 . The mean age was $46 \pm 17.1$ years, and 87 patients (45\%) were men. Only 52 patients $(26.8 \%)$ used emergency rescue teams, and 99 patients $(51 \%)$ visited by themselves. Mean time latency from symptom onset to hospital visit was $62 \pm 70.5$ minutes. The most common cause of anaphylaxis was drug (56.2\%) followed by food (26.8\%), insects (9.8\%), and exercise $(1.5 \%)$ in descending order. Seven patients were not assessed. Forty-seven patients $(24.2 \%)$ have a previous history of anaphylaxis, and among them, $70 \%$ of those patients had experienced anaphylaxis caused by 
the same suspicious agent. More than half of the patients $(\mathrm{n}=115,59.3 \%)$ had an allergic disease other than anaphylaxis. Cutaneous (88.7\%) and respiratory (72.7\%) symptoms were frequent. Hypotension was presented in 114 patients (58.8\%). Cardiovascular symptoms except

Table 1. Characteristics of patients of anaphylaxis who visited our emergency departments $(n=194)$

\begin{tabular}{|c|c|}
\hline Characteristic & Value \\
\hline Age, yr & $46 \pm 17.1$ \\
\hline Male sex & $87(44.8)$ \\
\hline \multicolumn{2}{|l|}{ Type of visit } \\
\hline Themselves & $99(51.0)$ \\
\hline Emergency rescue team & $52(26.8)$ \\
\hline Transfer from other hospital & $43(22.2)$ \\
\hline $\begin{array}{l}\text { Time interval from symptom onset to } \\
\text { visit, } \text { min }^{a}\end{array}$ & $62 \pm 70.5$ \\
\hline \multicolumn{2}{|l|}{ Suspicious cause } \\
\hline Drug & $109(56.2)$ \\
\hline Food & $52(26.8)$ \\
\hline Insect & $19(9.8)$ \\
\hline Exercise & $3(1.5)$ \\
\hline Others & $4(2.1)$ \\
\hline Not assessed & $7(3.6)$ \\
\hline History of anaphylaxis & $47(24.2)$ \\
\hline Same suspicious cause & $33(17.0)$ \\
\hline Others & $5(2.6)$ \\
\hline Unknown & $9(4 \cdot 6)$ \\
\hline $\begin{array}{l}\text { History of allergic disease other than } \\
\text { anaphylaxis }\end{array}$ & $77(39.7)$ \\
\hline Urticaria and/or angioedema & $42(21.6)$ \\
\hline Allergic rhinitis & $35(18.0)$ \\
\hline Asthma & $14(7 \cdot 2)$ \\
\hline Others & $24(12.4)$ \\
\hline \multicolumn{2}{|l|}{ Symptoms } \\
\hline Cutaneous & $172(88.7)$ \\
\hline Respiratory & $141(72.7)$ \\
\hline Hypotension & $114(58.8)$ \\
\hline Neurologic & $85(43.8)$ \\
\hline Gastrointestinal & $50(25.8)$ \\
\hline Cardiovascular (except hypotension) & $45(23.2)$ \\
\hline
\end{tabular}

Values are presented as mean \pm SD or number (\%).

${ }^{a}$ Patients who were transferred from other hospitals were excluded. for hypotension such as chest tightness or palpitation, etc. were present in 45 patients $(23.2 \%)$.

Table 2. Management of anaphylaxis patients who visited our emergency departments $(n=184)$

\begin{tabular}{lc}
\hline Type of managements & No. $(\%)$ \\
\hline Management with epinephrine & $114(62)$ \\
$\begin{array}{l}\text { Systemic steroid, antihistamine and hy- } \\
\text { dration }\end{array}$ & $95(52)$ \\
Systemic steroid and antihistamine & 0 \\
Antihistamine and hydration & $2(1)$ \\
\hline Hydration & $2(1)$ \\
Unknown & $15(8)$ \\
\hline Management without epinephrine & $70(38)$ \\
Systemic steroid, antihistamine and & $51(28)$ \\
hydration & $2(1)$ \\
Systemic steroid and antihistamine & $3(2)$ \\
Antihistamine and hydration & $3(2)$ \\
\hline Hydration & $11(6)$ \\
\hline Unknown & $10(5)$ \\
\hline Management with other inotropics & $2(1)$ \\
\hline With epinephrine & \\
\hline Without epinephrine &
\end{tabular}

Types of other inotropics (dopamine: 7 cases; norepinephrine: 5 cases; atropine: 1 case).

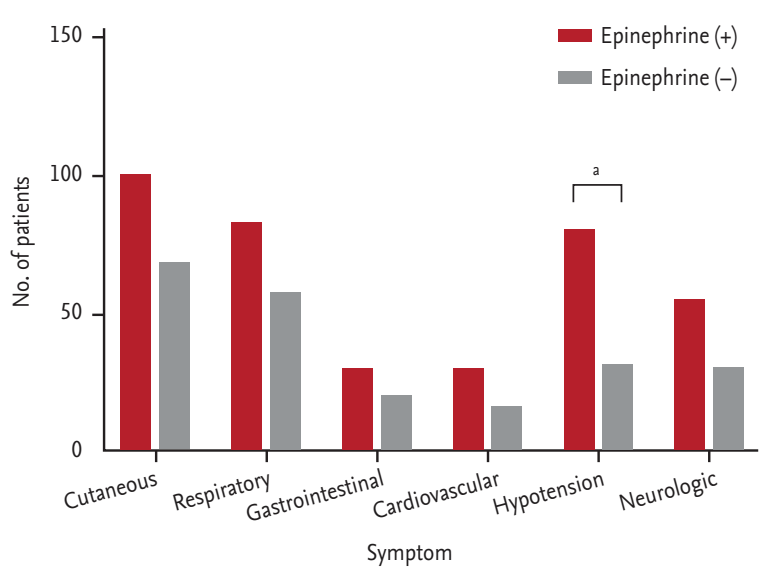

Figure 1. Associated symptoms with injection of epinephrine in patients of anaphylaxis who visited our emergency department $(n=184)$. ${ }^{a}$ Hypotension was significant associated symptom with injection of epinephrine in patients of anaphylaxis $(p=0.000$, Pearson chi-square test). 


\section{Therapeutic options and prescription patterns in emergency departments}

Information about the types of management was evaluated in 184 patients and described in Table 2. Epinephrine was injected in 114 patients. Seventy patients were not injected with epinephrine, and among them, two patients were infused with other types of inotropics. The route and dose of epinephrine are shown in Table 3.

Table 3. Types of administration of epinephrine and systemic steroid in patients of anaphylaxis

\begin{tabular}{|c|c|}
\hline Variable & Value \\
\hline Epinephrine & 114 \\
\hline $\begin{array}{l}\text { Time latency from visit to epinephrine } \\
\text { injection, min }\end{array}$ & $26 \pm 38.2$ \\
\hline \multicolumn{2}{|l|}{ Route of initial injection } \\
\hline Intramuscular & $68(59.6)$ \\
\hline Intravascular bolus & $20(17 \cdot 5)$ \\
\hline Subcutaneous & $19(16.7)$ \\
\hline Nebulizer & $4(3.5)$ \\
\hline Intravascular infusion & $3(2.6)$ \\
\hline \multicolumn{2}{|l|}{ Dose of initial injection, mg } \\
\hline Intramuscular & $0.3 \pm 0.10$ \\
\hline Intravascular bolus & $0.3 \pm 0.36$ \\
\hline Subcutaneous & $0.3 \pm 0.18$ \\
\hline Nebulizer & $2.3 \pm 0.50$ \\
\hline Intravascular infusion & $2.1 \pm 2.76$ \\
\hline Patients who needed repeating dose & $24(21.1)$ \\
\hline $\begin{array}{l}\text { Patients who needed continuous } \\
\text { infusion after initial dose }\end{array}$ & $1(0.9)$ \\
\hline Systemic steroid & 148 \\
\hline \multicolumn{2}{|l|}{ Type of steroid } \\
\hline Dexamethasone & $79(53 \cdot 4)$ \\
\hline Methylprednisolone & $74(50.0)$ \\
\hline Hydrocortisone & $27(18.2)$ \\
\hline Cortisone & $1(0.7)$ \\
\hline \multicolumn{2}{|l|}{ Dose of steroid ${ }^{\mathrm{a}}, \mathrm{mg} / \mathrm{kg}$} \\
\hline Methylprednisolone & $2.2 \pm 1.65$ \\
\hline Hydrocortisone & $0.7 \pm 0.46$ \\
\hline Dexamethasone & $0.6 \pm 0.50$ \\
\hline Cortisone & O.1 (single case) \\
\hline
\end{tabular}

Values are presented as mean \pm SD or number (\%).

${ }^{a}$ Dose of steroid was converted as equivalent dose of methylprednisolone.
The time latency from visit to epinephrine injection was $26 \pm 38.2$ minutes (maximum 214 minutes). Sixty-eight patients (59.6\%) were initially injected with epinephrine intramuscularly, and 20 patients $(17.5 \%)$ were injected with epinephrine by intravascular bolus. The mean dose of the initial intramuscular injection was $0.3 \pm 0.1 \mathrm{mg}$. Twenty-four patients (21.1\%) needed a second epinephrine injection, and one patient needed continuous infusion after the initial epinephrine injection (Table 3). Hypotension was a significant associated symptom with the injection of epinephrine in anaphylaxis patients $(p$ $=0.000$ ) (Fig. 1). Among the patients injected with epinephrine, most patients (95 patients) were treated with systemic steroid, antihistamine and hydration. Among

Table 4. Progression and education of anaphylaxis patients who visited our emergency departments $(n=180)$

\begin{tabular}{|c|c|}
\hline Variable & Value \\
\hline \multicolumn{2}{|l|}{ Progression $^{\mathrm{a}}$} \\
\hline \multicolumn{2}{|l|}{ Results of visit } \\
\hline Discharge & $155(86)$ \\
\hline \multicolumn{2}{|l|}{ Admission } \\
\hline Ward & $21(12)$ \\
\hline Intensive care unit & $3(2)$ \\
\hline Transfer & $1(1)$ \\
\hline Observation time in ED, hr & $12 \pm 25 \cdot 7(1-194)$ \\
\hline $\begin{array}{l}\text { Patients who were injected } \\
\text { epinephrine }\end{array}$ & $15 \pm 29 \cdot 3(1-192)$ \\
\hline $\begin{array}{l}\text { Patients who were not injected } \\
\text { epinephrine }\end{array}$ & $5 \pm 4.7(1-27)$ \\
\hline \multicolumn{2}{|l|}{ Education } \\
\hline $\begin{array}{l}\text { Education about avoidance of } \\
\text { suspicious agents }\end{array}$ & $23(13)$ \\
\hline $\begin{array}{l}\text { Prescription and education of } \\
\text { epinephrine auto-injector }\end{array}$ & $5(3)$ \\
\hline \multicolumn{2}{|l|}{$\begin{array}{l}\text { Request a consultation to allergy } \\
\text { department }\end{array}$} \\
\hline At emergency departments & $34(19)$ \\
\hline To outpatient department ${ }^{\mathrm{b}}$ & $72(40)$ \\
\hline
\end{tabular}

Values are presented as number (\%) or mean \pm SD (minimum-maximum).

ED, emergency department.

${ }^{\mathrm{a}} 14$ (7.2\%) of against medical advice discharge, they were not included in this analysis.

${ }^{\mathrm{b}}$ The number of patients who actually visit the outpatient department: 56 (77.8\%). 
Table 5. Associated factors affecting the duration of stay in emergency department in patients of anaphylaxis $(n=142)$

\begin{tabular}{|c|c|c|}
\hline Variable & Mean $\pm \mathrm{SD}, \mathrm{hr}$ & $p$ value \\
\hline Age & & $0.237\left(R^{2}=0.010, B=0.104\right)$ \\
\hline Time latency from symptom onset to ED visit & & $0.048\left(R^{2}=0.029, \mathrm{~B}=-0.066\right)$ \\
\hline Initial dose of epinephrine & & $0.685\left(R^{2}=0.002, B=-2.496\right)$ \\
\hline Time latency of epinephrine injection & & $0.170\left(R^{2}=0.024, \mathrm{~B}=0.105\right)$ \\
\hline Gender & & 0.162 \\
\hline Male & $6.9 \pm 7.46$ & \\
\hline Female & $10.2 \pm 23.29$ & \\
\hline Cutaneous symptom & & 0.120 \\
\hline$(+)$ & $7.0 \pm 8.13$ & \\
\hline$(-)$ & $42.1 \pm 60.55$ & \\
\hline Respiratory symptom & & 0.379 \\
\hline$(+)$ & $8.7 \pm 16.17$ & \\
\hline$(-)$ & $12.5 \pm 28.69$ & \\
\hline Gastrointestinal symptom & & 0.271 \\
\hline$(+)$ & $14.4 \pm 33.63$ & \\
\hline$(-)$ & $7.9 \pm 9.62$ & \\
\hline Cardiovascular symptom & & 0.379 \\
\hline$(+)$ & $19.1 \pm 35.38$ & \\
\hline$(-)$ & $5.8 \pm 6.01$ & \\
\hline Hypotension & & 0.004 \\
\hline$(+)$ & $13 \cdot 32 \pm 24 \cdot 34$ & \\
\hline$(-)$ & $4.8 \pm 5 \cdot 54$ & \\
\hline Neurologic symptom & & 0.118 \\
\hline$(+)$ & $12.5 \pm 26.77$ & \\
\hline$(-)$ & $6.6 \pm 8.93$ & \\
\hline Injection of epinephrine & & 0.014 \\
\hline Injected & $12.1 \pm 23.30$ & \\
\hline Not injected & $4 \cdot 5 \pm 3 \cdot 34$ & \\
\hline
\end{tabular}

Linear regression and independent-samples $t$ test were used in analysis.

ED, emergency department.

the patients who were not injected with epinephrine, three patients did not receive antihistamine but were injected with systemic steroid and hydrated as well. Dexamethasone was the most common steroid which was injected (Table 3).

\section{The progression and education status}

The progression of 180 patients were analyzed because 14 patients were discharged against medical advice (AMA) (Table 4). One hundred and fifty-five patients were discharged from the EDs, and 24 patients needed to be readmitted. One patient was managed at the intensive care unit. The mean time for overall observation in the ED was $12 \pm 25.7$ hours. In patients who were injected with epinephrine, the mean observation time was 15 \pm 29.3 hours. On the other hand, the mean observation time in patients who were not injected with epinephrine was just $5 \pm 4.7$ hours.

The education status in the EDs is described in Table 4. The number of patients who underwent education on 
avoiding suspicious agents was 23 (13\%). Only five patients (3\%) were prescribed auto-injective epinephrine at the ED. Moreover, only 34 patients $(19 \%)$ requested a consultation from the allergy department at the ED, and 72 patients (40\%) were sent to the outpatient department after discharge. However, among them, only 56 patients actually visited the outpatient department. Among them 10 patients (17.9\%) were prescribed auto-injective epinephrine. And 34 patients (60.7\%) were confirmed cause of anaphylaxis by provocation test or serum antibody.

\section{Associated factors affecting the duration of stay in the emergency department}

Except for AMA discharge patients, a total of 142 patients who had complete information were analyzed (Table 5). There was a tendency to stay longer in patients who visited earlier after symptom onset $\left(R^{2}=0.029, \mathrm{~B}=-0.066\right.$, $p=0.048)$. The duration of the ED stay was significantly longer in patients with hypotension (13.32 \pm 24.34 hours vs. $4.8 \pm 5.54$ hours, $p=0.004)$ and those were treated with epinephrine injection $(12.1 \pm 23.30$ hours vs. $4.5 \pm$ 3.34 hours, $p=0.014)$. Age, initial dose of epinephrine, and time latency of the epinephrine injection were not associated with the duration of the ED stay. Gender and organ specific symptoms were also not associated with the duration of the ED stay.

\section{DISCUSSION}

To our knowledge, there have been many studies on the clinical features and management of anaphylaxis [6-8], but there have been only a few studies on whether education was appropriately provided in the actual clinical field especially in Korea. In our study, we evaluated how many patients were treated according to guidelines in real situations. In addition, we could encourage the appropriate management and education by presenting these problems. Unfortunately, inappropriate management and education were done rather than following the international guideline in the actual clinical field [5].

The time to visit the ED from symptom onset was over 60 minutes. In one study in Korea, the mean time to arrival at hospital after development of symptoms was even 279.8 minutes [4]. Because prompt intervention is very important in anaphylaxis, the delayed injection of epinephrine is associated with a poor prognosis. Patients should visit the ED as soon as possible. In fact, many patients transported themselves to the ED. If they went to the hospital using an ambulance, they would have arrived earlier. Critical time is consumed on the road during transportation to the hospital. For a patient who has experienced anaphylaxis more than one time, he or she must be educated to request the help of paramedics. Like cardiopulmonary resuscitation, anaphylaxis should be educated all people about first aid procedures. Additionally, epinephrine auto-injectors should be kept by paramedics in the ambulance, and they should be educated on how to use them. According to the international guideline, it is recommended to inject epinephrine intramuscularly [2] because injection through other routes, especially intravenous bolus, has risks of cardiovascular complications and overdose [9]. The optimal intramuscular dose is $0.5 \mathrm{mg}$ maximum in adults and $0.3 \mathrm{mg}$ in children [2]. Actually, there were many patients who were not injected intramuscularly with epinephrine. About $40 \%$ of the patients were not injected intramuscularly with epinephrine but instead through other routes. Furthermore, the dose of epinephrine ( 0.3 $\pm 0.10 \mathrm{mg}$ intramuscularly) was lower than recommended dose according to WAO guideline ( $0.01 \mathrm{mg} / \mathrm{kg}$, if the patient was over $50 \mathrm{~kg}, 0.5 \mathrm{mg}$ of epinephrine should be injected) [2]. There was a tendency (although we did not analyze it statistically) that mean dose of epinephrine was higher in patient of single dose epinephrine injected intramuscularly ( $0.325 \mathrm{mg}$ in 53 patients) than multiple dose injected ( $0.3 \mathrm{mg}$ in 15 patients). One patient was injected just $0.3 \mathrm{mg}$ dose of epinephrine intramuscularly four times. Three patients without epinephrine injections were only just hydrated. In patients who were not injected with epinephrine, they fortunately recovered in all cases and had a shorter observation time than the patients with epinephrine injections, and those patients would have only mild anaphylaxis. The negative relation between time latency from symptom onset to ED visit and the duration of the ED observation could be caused by the same reason. Here, one question arises. That is whether the patient with mild anaphylaxis needs epinephrine. However, we cannot predict any further reactions after the initial symptom; thus, epinephrine must be injected into all anaphylaxis patients promptly. In our study, the associated symptom with the injec- 
tion of epinephrine was hypotension, and the patients without hypotension could be underdiagnosed and be not injected with epinephrine. According to the WHO criteria, we could diagnose patients without hypotension as anaphylaxis if they fulfill other criteria [5]. Thus, clinicians need to pay more attention when diagnosing anaphylaxis. It should be educated that anaphylaxis can be diagnosed without hypotension.

Corticosteroid was used in most cases to prevent a delayed reaction despite of unclear efficacy [2]. The WAO guideline recommend it as second line medication [2]. Dexamethasone and methylprednisolone were preferred. There have been no studies in which corticosteroid was more effective, and the recommended dose of corticosteroid was extrapolated from acute asthma treatment [2]. In the global initiative for the asthma guideline, they recommend $1 \mathrm{mg} / \mathrm{kg}$ of prednisolone (maximum 50 $\mathrm{mg}$ ) [10]. In our study, there was a tendency to use a low dose corticosteroid in anaphylaxis when other types of corticosteroids were also used except for methylprednisolone. Additionally, a higher dose of methylprednisolone was used instead of the recommended dose. Corticosteroid was used to prevent biphasic anaphylaxis [11], but more studies are needed to determine the efficacy, adequate dose, and type. In addition, the physicians should understand the purpose and unclear efficacy.

Education on avoiding the causative agent was also important but not sufficient. Just 23 patients (13\%) were educated to avoid suspicious agents. The most frequent causative agent was drug. In these cases, the causative drug could be identified through the medical history and with suitable tests. We could prevent anaphylaxis caused by same drug if the agent is defined and avoided. For this, active evaluation and education on avoidance by doctors are needed. In many cases, education about avoidance and the use of an epinephrine auto-injector were not recorded. Hospitals should provide education programs and record this education to prevent any legal problems. One good method is to consult an allergist for an evaluation and follow-up. There was a study that reported follow-up was effective in achieving good outcomes [12]. In that study, $35 \%$ of the patients who were diagnosed with anaphylaxis in the ED had an alteration in the diagnosis or trigger [12]. Sometimes, it could be difficult to diagnose a patient with anaphylaxis due to vague symptoms and the absence of hypotension or ur- ticaria. Underdiagnosis could lead to under-treatment especially epinephrine [13]. It is important to confirm the diagnosis and to define the trigger for further education and prevention. In our study, just 106 patients transferred to an allergist at the ED or to an out-patient department. Among them, 90 patients actually met an allergist (34 patients at ED and 56 patients at out-patient department). Seventy-eight percent of the patients who were transferred to an outpatient department actually visited an allergist, so compliance was not low. Among them, 10 patients (17.9\%) were prescribed epinephrine auto-injectors. If close cooperation with the ED and an allergist is possible, more help such as diagnosis, education and emotional support can be provided to anaphylaxis patients. In addition, it is necessary to educate the medical staff that anaphylaxis has a risk of recurrence to trigger re-exposure, so trigger should be evaluated at first attack. And they should know that anaphylaxis could be diagnosed without hypotension.

Our study has some limitations. First, the patient group did not represent the general state of EDs in Korea because we evaluated just three hospitals. Thus, more studies are needed. Second, we enrolled patients by searching the ICD codes inputted subjectively, so some patients who were recoded with other diagnoses such as hypotension could be missed. Third, it could be possible that they did not record education although they educated patients because our study depended on medical records.

In conclusion, many patients received the appropriate management of anaphylaxis, but some patients received a little different management from the guideline such as epinephrine injection. An education and promotion program on anaphylaxis is needed for medical staff especially emergency healthcare workers. Education on avoiding triggers and an emergency action plan are important to avoid recurrence of anaphylaxis and to get a good prognosis. It could be helpful to request an allergist for follow-up after acute management by emergency healthcare workers.

\section{KEY MESSAGE}

1. Associated factor with epinephrine injection was hypotension in our study population. 
2. Some patients received a little different management from the guideline such as epinephrine injection.

3. An education and promotion program on anaphylaxis is needed for medical staff.

\section{Conflict of interest}

No potential conflict of interest relevant to this article was reported.

\section{REFERENCES}

1. Brown SG, Stone SF, Fatovich DM, et al. Anaphylaxis: clinical patterns, mediator release, and severity. J Allergy Clin Immunol 2013;132:1141-1149.

2. Simons FE, Ardusso LR, Bilo MB, et al. World Allergy Organization guidelines for the assessment and management of anaphylaxis. World Allergy Organ J 2011;4:13-37.

3. Lieberman P, Camargo CA Jr, Bohlke K, et al. Epidemiology of anaphylaxis: findings of the American College of Allergy, Asthma and Immunology Epidemiology of Anaphylaxis Working Group. Ann Allergy Asthma Immunol 2006;97:596-602.

4. Ye YM, Kim MK, Kang HR, et al. Predictors of the severity and serious outcomes of anaphylaxis in Korean adults: a multicenter retrospective case study. Allergy Asthma Immunol Res 2015;7:22-29.

5. Simons FE, Ardusso LR, Bilo MB, et al. 2012 Update:
World Allergy Organization Guidelines for the assessment and management of anaphylaxis. Curr Opin Allergy Clin Immunol 2012;12:389-399.

6. Yang MS, Lee SH, Kim TW, et al. Epidemiologic and clinical features of anaphylaxis in Korea. Ann Allergy Asthma Immunol 2008;100:31-36.

7. Jang GC, Chang YS, Choi SH, et al. Overview of anaphylaxis in Korea: diagnosis and management. Allergy Asthma Respir Dis 2013;1:181-196.

8. Moon IJ, Park HJ, Kim SR, et al. Drug-induced anaphylaxis in a single Korean tertiary hospital. Korean J Med 2015;88:281-287.

9. Campbell RL, Bellolio MF, Knutson BD, et al. Epinephrine in anaphylaxis: higher risk of cardiovascular complications and overdose after administration of intravenous bolus epinephrine compared with intramuscular epinephrine. J Allergy Clin Immunol Pract 2015;3:76-80.

10. Global Initiative for Asthma. Global strategy for asthma management and prevention 2014 [Internet]. Global Initiative for Asthma (GINA), c2016 [cited 2017 Oct 13]. Available from: http://ginasthma.org.

11. Simons FE, Ardusso LR, Dimov V, et al. World Allergy Organization Anaphylaxis Guidelines: 2013 update of the evidence base. Int Arch Allergy Immunol 2013;162:193-204.

12. Campbell RL, Park MA, Kueber MA Jr, Lee S, Hagan JB. Outcomes of allergy/immunology follow-up after an emergency department evaluation for anaphylaxis. J Allergy Clin Immunol Pract 2015;3:88-93.

13. Sclar DA, Lieberman PL. Anaphylaxis: underdiagnosed, underreported, and undertreated. Am J Med 2014;127(1 Suppl):S1-S5. 
Supplementary Table 1. Distribution of patients by World Allergy Organization diagnostic criteria for anaphylaxis

\begin{tabular}{|c|c|}
\hline Criteria & No. (\%) \\
\hline Criteria $_{1}{ }^{\mathrm{a}}$ & $73(37.6)$ \\
\hline Criteria $2^{b}$ & $110(56.7)$ \\
\hline Criteria $3^{c}$ & $2(1.0)$ \\
\hline
\end{tabular}

Nine patients could not be assessed because of insufficient information.

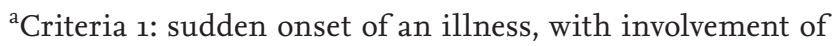
the skin, mucosal tissue, or both and at least one of the following: sudden respiratory symptoms and signs or sudden reduced blood pressure (BP) or symptoms of end-organ dysfunction.

${ }^{\mathrm{b}}$ Criteria 2: two or more of the following that occur suddenly after exposure to a likely allergen or other trigger for that patient: sudden skin or mucosal symptoms and signs, sudden respiratory symptoms and signs, sudden reduced BP or symptoms of end-organ dysfunction or sudden gastrointestinal symptoms.

${ }^{\mathrm{c}}$ Criteria 3: reduced BP after exposure to a known allergen for that patient. 